\title{
Discussion on the Role of Family in Kindergarten Curriculum Reform
}

\author{
Rang Jiaxin \\ IvyGate International Education Group, Hangzhou, Zhejiang, China \\ Seven_rang@163.com
}

Keywords: Family, kindergarten curriculum reform, parents, countermeasures

\begin{abstract}
In order to explore the role of family in reform of kindergarten curriculum, first of all, the relationship between family and the kindergarten curriculum reform is discussed mainly from two aspects. On the one hand, the kindergarten provides help and support for parents because only when the overall quality of parents is improved can they create a good family environment for children. On the other hand, the kindergarten is assisted and supported by parents in that the cooperation between parents and the kindergarten is necessary. Thirdly, the practice of parents participating in kindergarten curriculum reform is discussed. Finally, for achieving a better kindergarten curriculum reform, some countermeasures are put forward. The results show that parents play an essential role in the kindergarten curriculum reform so that the participation of parents is necessary. To sum up, in order to promote the quality of kindergarten curriculum reform, the joint efforts of parents and teachers are needed.
\end{abstract}

\section{Introduction}

In the past few years, China's kindergarten education has made considerable progress, showing unprecedented prosperity. But in the face of the second decade of the twenty-first century, kindergarten education has become the focus of national attention and questioning voices continue. Faced with the challenges of the new era, the most confusing part of kindergartens is that even though they know there are problems in the curriculum and need to be improved, they do not know where to start. How should kindergartens choose curriculum models or curriculum materials? How to diagnose the rationality and scientificity of the courses that have been implemented? How to further improve the existing curriculums? These problems are unavoidable in every kindergarten.

The kindergarten curriculum presents a variety of curriculum schemes on the road to multi-independent development. Every kindergarten should have a curriculum plan that combines the reality of the kindergarten and reflects the characteristics of the kindergarten. However, in practice, it is found that there are some problems in the curriculum plan of the kindergarten, such as vague ideas, lack of goals, overload of contents, and single implementation method. As a result, it is urgent to reform the kindergarten curriculum that has various problems, so as to improve the kindergarten education. Parents are the important factor affecting the kindergarten curriculum selection because they will affect the development of children, and ultimately affect the realization of kindergarten education goals. Therefore, the relationship between parents and kindergarten 
curriculum is discussed firstly. Then, parents are enabled to participate in the kindergarten curriculum reform to play their role. At last, the suggestions for promoting a better kindergarten curriculum reform are proposed.

\section{Literature review}

In recent years, kindergarten education is paid great attention to by educators, governments, and schools. The curriculum reform is also focused on by scholars at family and abroad. Scholars in domestic mainly talked about the evolution, implementation, rating system and other aspects of kindergarten curriculum. Li and Chen critically analyzed three major waves of ECC reform in China, with a particular emphasis on the social and cultural forces that have shaped the evolution and revolution of ECC in China. The analysis revealed the effects of these different forces in inducing change and how they propelled innovative reform of ECC. Furthermore, the history of adopting and adapting curriculum ideologies is deconstructed and modeled from other cultural contexts with the opposite concepts of cultural relativism and cultural universalism ( $\mathrm{Li}$ and Chen, 2017). Hu examined the degrees of congruence between two early childhood evaluation systems on various quality concepts: The Early Childhood Environment Rating Scale-Revised (ECERS-R) and Zhejiang's Kindergarten Quality Rating System (KQRS). Analysis of variance and post hoc least significant difference tests were employed to show the extent to which the ECERS-R ratings predict a kindergarten's placement on the KQRS (Hu, 2015). Based on the observation of 180 early childhood classrooms using the Classroom Assessment Scoring System (CLASS), Hu et al. found Chinese teachers scored lower on instruction support quality compared to international colleagues. $\mathrm{Hu}$ et al. also examined Chinese teachers' quality of interactions across settings (i.e., whole-group teaching, free play, routine/care, and outdoor play) and activities (i.e., language, math and science, and others) (Hu, Dieker, Yang and Yang, 2016). Taking the national agenda for reforming PSE at the start of the twenty-first century as the point of departure, Tan described and discussed the policies and strategies that have been introduced and implemented for preschool quality enhancement in the past 15 years. Opportunities and challenges associated with implementing recommendations for quality enhancement were discussed and suggestions to further enhance PSE in Singapore were explored (Tan, 2017).

Foreign scholar also focused greatly on kindergarten education. Nyland and Ng explored early childhood curriculum reform in Australia and Singapore in order to identify international trends in early childhood education (ECE), similarities in curriculum reform initiatives and implementation strategies adopted. They also discussed the role of teachers in the reform process and question the reliance on one stakeholder group to ensure planned changes to the ECE reform agenda occur (Nyland and Ng, 2016). Through comparing the diagnostic test scores of incoming students in an Irish university in the years before and after the reform, Prendergast and Treacy found that the reformed approach coincided with a decline in students' technical algebraic skills. However, interviews with practicing mathematics teachers revealed that this decline was not a direct result of the functions-based approach, but rather of a mixture of approaches being implemented in classrooms (Prendergast and Treacy, 2018). Polly et al. investigated the impacts of a year-long professional development program on Kindergarten teachers' beliefs and practices and the association of these changes with student achievement in mathematics measured by curriculum-based instruments. They also identified that no teacher-related variables except for their years of teaching were associated with classroom instructional quality (Polly, Wang, Lambert, Martin, McGee, Pugalee and Lehew, 2017).

To sum up, the above researches mainly discussed the kindergarten curriculum, but they do not discuss the role of parents in kindergarten curriculum reform. Therefore, based on the above studies, 
the role of parents in kindergarten curriculum reform is further explored. Ryder examined individual teachers' beliefs, practices and reflections associated with curriculum reform, the response of teacher communities to reform (e.g. within school departments), and teachers' (and other stakeholders') experiences across school systems. He also identified a wide range of factors influencing teachers' responses and highlighted issues of authority, professionalism and the process of meaning-making in response to external curriculum reform. The discussion section identifies important areas for future research and gives recommendations for the design of curriculum policies that recognize and support the professionalism of science teachers (Ryder, 2015).

\section{The relationship between family and kindergarten curriculum reform}

\subsection{Help and support of parents}

The interactive relationship between kindergarten and family is the closest social and cultural situation to children. These social situations play an important role in the development and learning of young children. With the changes of the times, social problems emerge in endlessly, family structure, the roles of parents and other family members, and parents' responsibilities are always in a continuous state of change. Kindergartens are also constantly challenged. It is urgent to solve how use the best content to satisfy young children, their families and today's society demand. Kindergartens need creative ways to provide services to all types of children and families.

The challenges faced by kindergartens are how to meet these needs by adapting to cultural development. Generally speaking, the approach more recognized by the kindergarten education sector is, on the one hand, to provide good kindergarten education, on the other hand, by providing education services for families of young children, to help young children get a better family education environment. There are two main modes of kindergartens providing services for children and their parents: indirect mode: to have an impact on families through children and communities; direct mode: to provide direct education for family members in child-rearing, literacy education and educational counseling programs, help to solve daily life problems, and provide community institutions with reference. The direct help mode is not only practical but also actually needed. Because helping families to exercise duties means that everyone benefits, and that everyone in the family, mothers, fathers and grandparents, can better help them and their children.

The mode of providing teaching and services directly to children and parents through the family unit is called "family-centered teaching", as shown in Figure 1. An example of family-centered teaching is America's "Always Sailing" (a government-funded family literacy program). The program combines adult literacy and parental training with early childhood education, breaking the cycle of illiteracy from the previous generation to the next. "Always Sailing" is conducted under the name of the Ameliorated American Education Act, and operated through the public school system.

There are three levels of family-centered curriculum and teaching. First of all, the purpose of these plans and materials is to help parents become qualified parents and teachers. To support parental roles, schools and teachers should provide parenting materials, guide parenting, and instill in families the idea of how to teach children reading and math skills through daily activities. At the second level, teaching is mainly to help parents solve their daily problems and disputes. For example, such teaching and information includes daily legal knowledge, the importance of nutritional meals and immunity enhancement, and how to use health services, which are integrated with the daily needs of families. At the third level, family-centered curriculum and teaching try to link classroom teaching with family learning. For example, 
providing textbooks for parents to read to their children will help to integrate learning in a school environment with learning in a home environment.
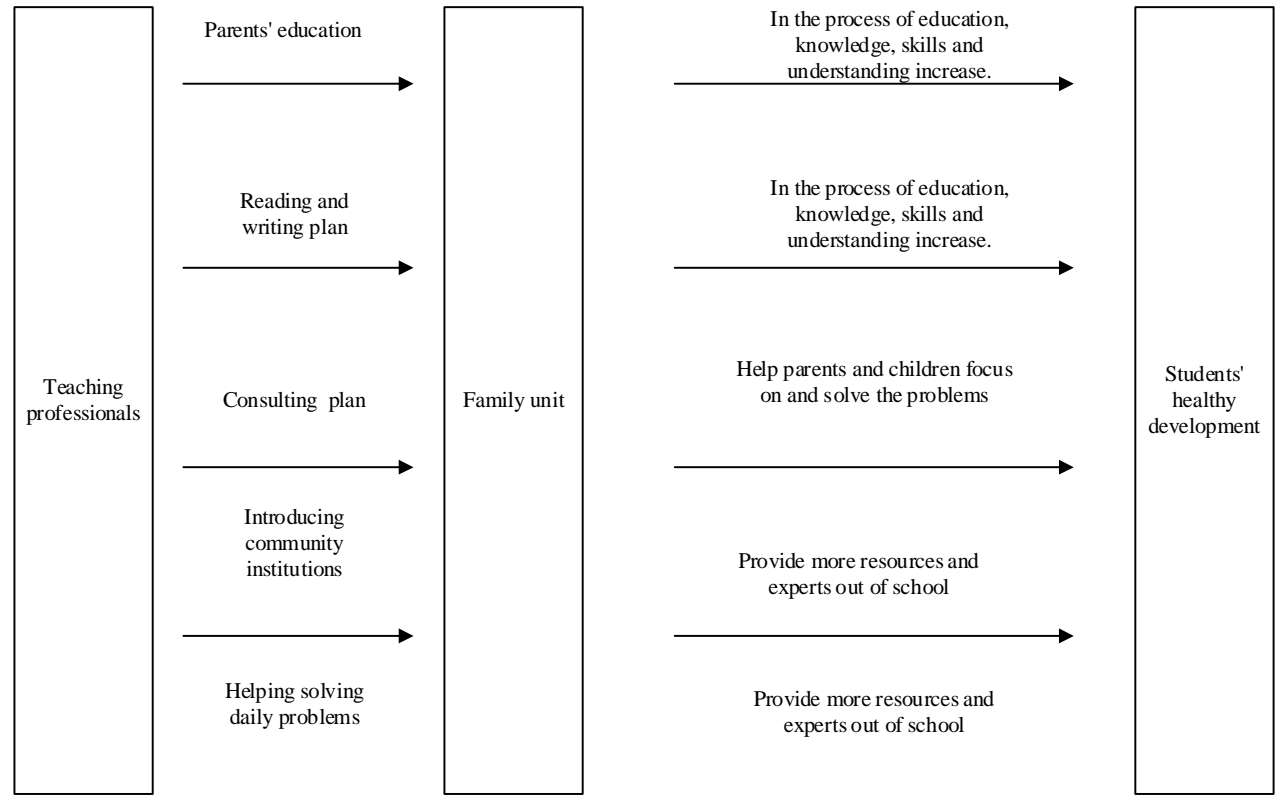

Figure 1. Family-centered teaching mode

Only when the overall quality of parents is improved can they create a good family ecology for young children and avoid economic crisis which is not conducive to their development. Therefore, not only pay attention to the cultivation of parents' educational wisdom should be paid attention to, but the cultivation of parents' all-round development as a person should be focused on.

\subsection{Assistance and support from parents}

It is necessary for the gardeners to cooperate with parents closely. We should recognize and respect the respective functions and roles of parents and professional workers in early childhood education, and recognize their benefits to young children. For example, parents can take on such tasks as providing opportunities, expressing recognition, interacting with children and setting an example in their children's learning. We should also see parents' support for children's learning in kindergarten curriculum implementation. Kindergartens should try to attract parents to participate in, so that parents understand the curriculum and feel the educational significance.

Kindergartens can seek support in many ways when considering and designing family and parental involvement programs. Task assignment: it is the most common and traditional way. That is to ask parents to assist special tasks in kindergartens or classes. Parents should bring some materials for kindergartens to carry out the curriculum at the teachers' request or on their own initiative. Parents with special skills should be invited to provide them with relevant information when teachers are not familiar with the content of children's interest and preparation for development. In addition, in some kindergartens, parents will be invited into kindergartens every semester to organize activities for children in person, such as the organizers and judges of sports, science and technology festivals, art festivals and other activities. In most kindergartens, teachers assign oral or hands-on homework to young children to be completed at home as a continuation or supplement to the preschool curriculum. In this way, parents can become tutors, assistants (parent volunteers), supervisors, curriculum resource providers, and the organizers, planners and assistants of major activities in kindergartens. Process participation: some parents 
are invited to participate in educational activities, such as curriculum review, curriculum development team members, evaluation and selection of curriculum plans, textbooks, and child development. Development task: this approach is mainly to help parents and family members develop skills that are beneficial to parents themselves and kindergartens. For example, parents' salon is held, special education skill courses for parents are offered, and experts are invited to give lectures on family education. The purpose is to help kindergarten achieve educational goals by improving parents' educational skills. If kindergartens can transcend the needs of specific institutions for specific purposes, all those involved in kindergarten education will be helped by the combination of the above methods.

\section{Participation of parents in kindergarten curriculum reform}

\subsection{Implementation approaches of kindergarten curriculum}

There are many ways to implement kindergarten curriculum. According to the relevant contents of Kindergarten Curriculum written by Professor Feng Xiaoxia, an expert in kindergarten education, kindergarten curriculum is divided into four aspects: daily life activities, teaching activities, environment creation and family cooperation. The implementation of kindergarten curriculum of 15 kindergartens is as follows:

Daily life activities:

The daily life activities of the kindergarten include activities before and after entering the kindergarten, washing and toileting, eating and snacking, napping and tidying. In the kindergartens surveyed, the above-mentioned life activities are basically arranged. However, to realize the educational value of children's daily life activities, it is necessary to rely on the conscious infiltration and guidance of teachers. Because of the randomness and concealment of life education, it is difficult to measure or evaluate. Therefore, the collected weekly planning texts of kindergartens are used to investigate whether there are specific life routine instructions in the weekly planning texts. This can reflect the importance and conscious utilization of kindergartens to children's daily life activities.

Table 1 . Whether there are specific life routine instructions in the weekly planning texts

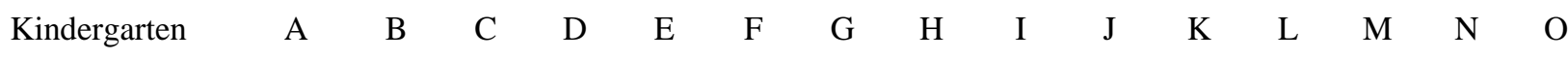

Life guidance Yes Yes No No Yes Yes Yes Yes Yes Yes No Yes Yes Yes Yes

According to the survey, $80 \%$ of kindergartens have routine instruction in their weekly plan texts. The following are the routine instructions on daily life written in the weekly plan of several kindergartens:

A: regular training in kindergartens: speak in a pleasant voice, and speak softly, not shouting.

B: kindergarten activities: clean up the desk before meals, put away the tableware neatly, and fold the clothes and pants neatly before napping.

F: kindergarten life activities special education: educate children quietly toilet, men and women go to the toilet separately, and individual kindergarten teachers to help take off pants.

I: kindergarten daily activities: wash well orderly, no push, snatch, pull phenomenon; seriously wash and wipe hands, and the method is correct.

M: kindergarten regular training: remind children not to grab chairs, gently handle, and do not shake chairs. 
O: kindergarten daily education: train children to listen to others; guide children to speak out their feelings boldly.

Teaching activities: kindergarten education needs standardized teaching activities, and children's development needs to be promoted through teaching. Therefore, effective teaching activities should be one of the main ways to implement kindergarten curriculum. The 15 kindergartens surveyed will organize and implement the curriculum through teaching activities, and focus on teaching, which is related to China's educational tradition, the current level of education development and teacher-child ratio and other factors. In reality, the problem is that the proportion of concentrated teaching activities in children's daily life activities is too large, affecting children to obtain useful experience and feeling through other means. The frequency of concentrated daily teaching activities in kindergartens is as follows:

Table 2. The frequency of concentrated daily teaching activities in kindergartens

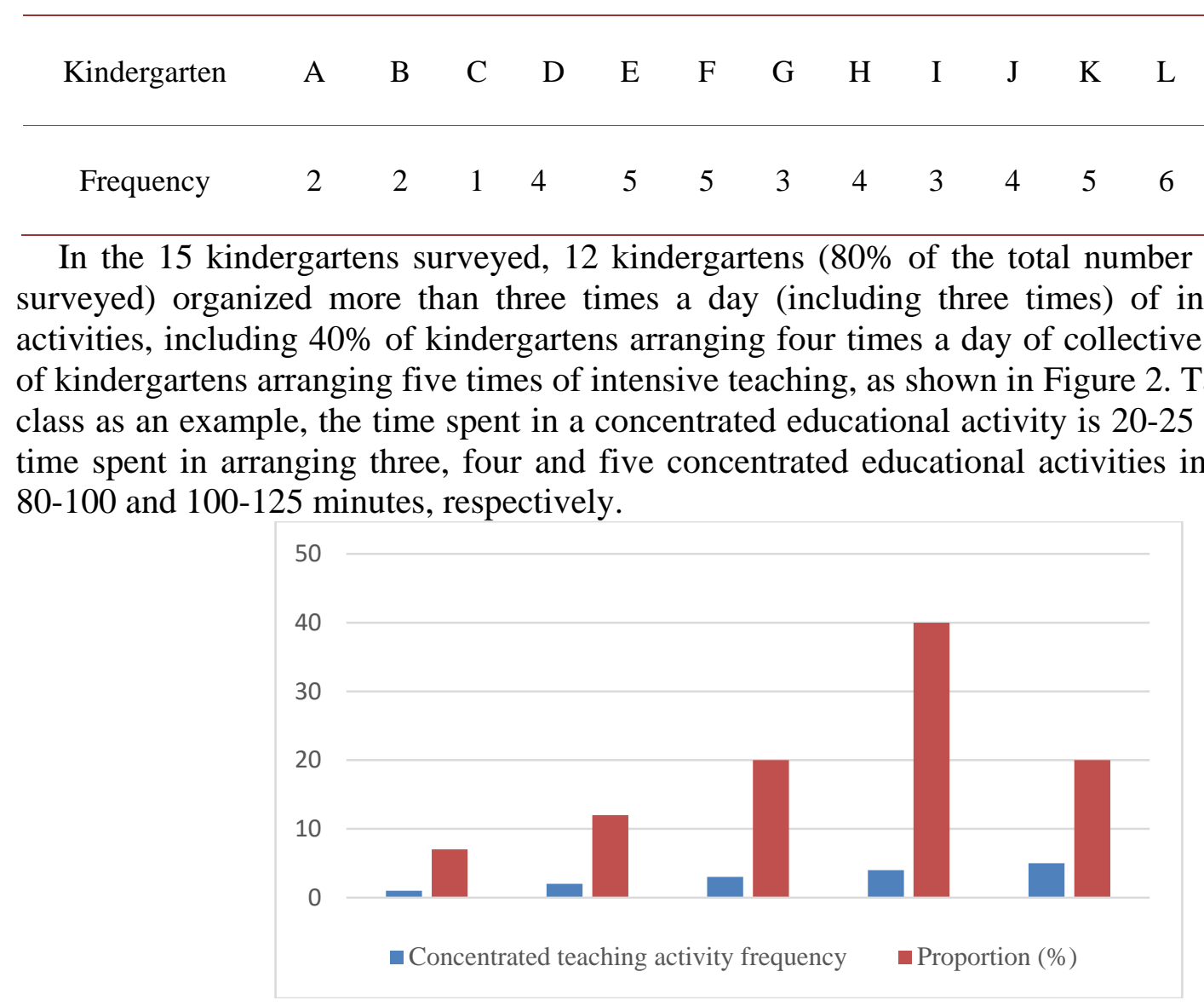

Figure 2. Frequency and proportion of concentrated teaching activities

Environment creation: environment is an important curriculum resource. By creating an educational environment, a subtle and beneficial influence can be exerted on children's physical and mental development. Each kindergarten presents a different environment and creation work. The kindergarten's environment creation is divided into three situations: the creation of a special environment around the theme, the display of simple pictures or works, and the seasonal or festival decoration.

Family cooperation: family is an important cooperative partner of kindergarten education that has abundant curriculum resources. Family cooperation is one of the important ways to implement kindergarten curriculum. Through interviews, 15 kindergartens are divided into regular family 
cooperation and festival family cooperation.

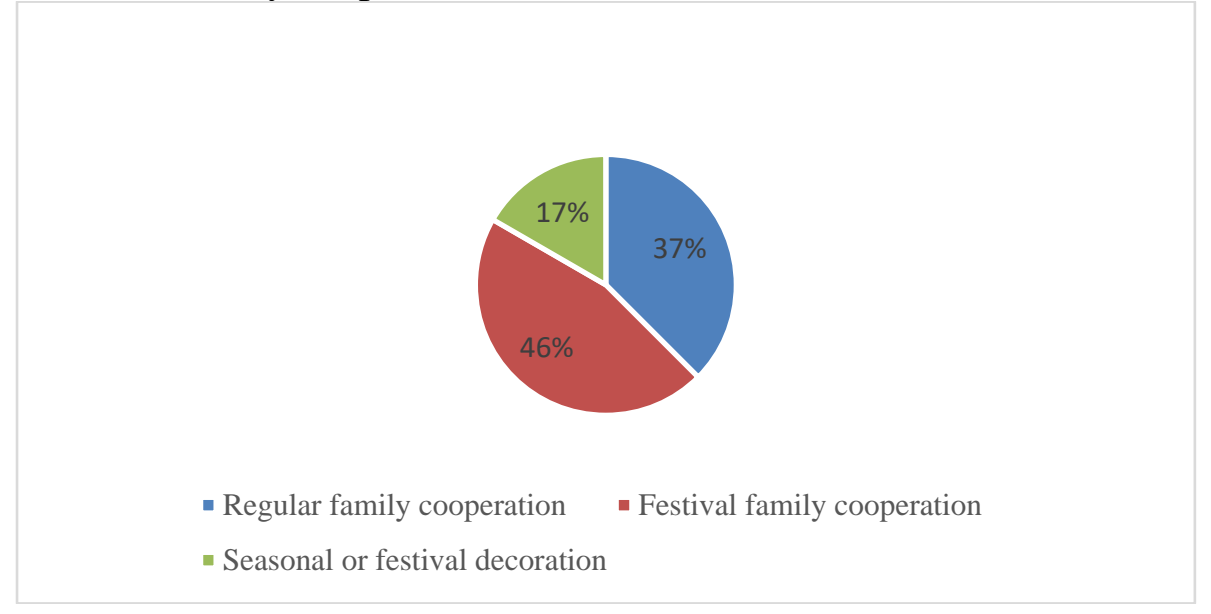

Figure 3. Proportion of kindergarten environment creation type

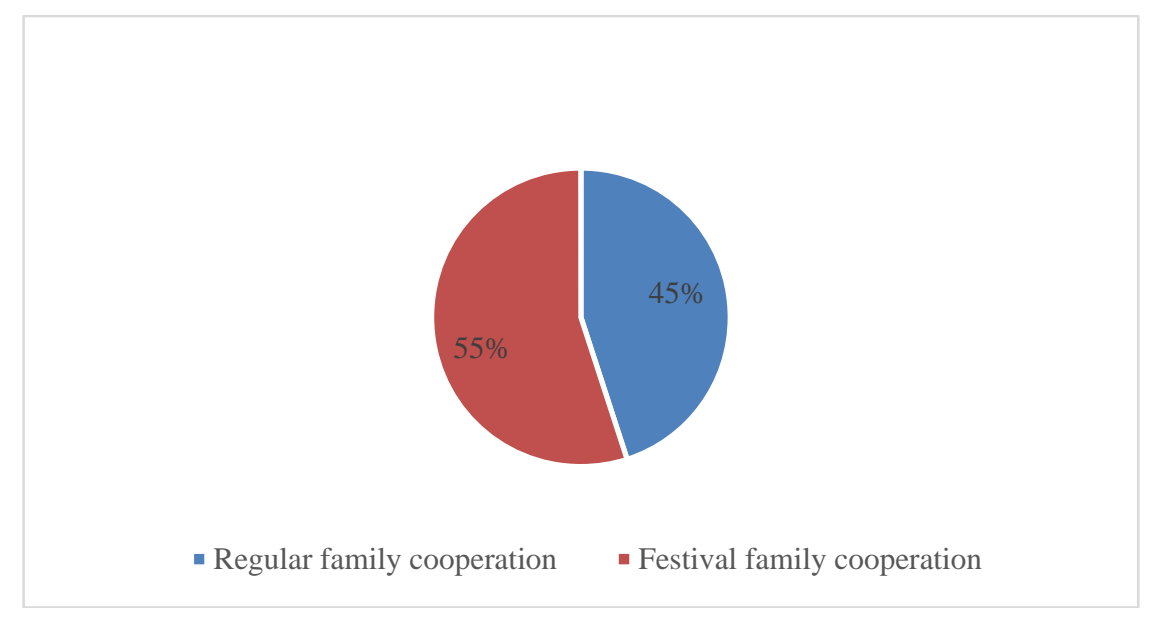

Figure 4. Proportion of kindergarten home cooperation types

\subsection{Enable parents to participate in the kindergarten curriculum reform}

For parents, a good first day is to let parents feel confident that the school will take care of their children and educate them well. Schools do not hold that parents should trust us to be a good school, but should seriously express how good we are. Environment is an important way for kindergartens to show their ability of education and care to their parents. Kindergartens should express their ability to parents through the environment, so that parents feel confident. Clean and comfortable is the basic requirement for the kindergarten environment, but also the basic respect for parents to visit the kindergarten. Therefore, in order to make parents feel confident and welcome in kindergartens, kindergartens should create a comfortable and tidy classroom environment.

In order to attract parents' attention, it should ensure that the content accords with the needs of parents. The situation of children in kindergartens are always the most concerned for parents. From the interview, it is learned that many parents do not know the existence of the parents' garden at first. But later because the children's works display bar is next to the parents' garden, children will guide parents to pay attention to their own works, and finally parents find the parents' garden. The enlightenment of this phenomenon is that the design of parents' garden can properly place the content related to children, such as the photos of children's activities, children's works and so on. In that the column plate is small and can't put too much child-related content, but slowly putting some 
will gradually attract the attention of parents.

\subsection{Guide parents to participate in the kindergarten curriculum reform}

Parents may be passive at the beginning of participating in the kindergarten curriculum. But through constant involvement, they can slowly participate in the curriculum. In order to encourage them, teachers can show their parents' abilities through some activities and cultivate parents' confidence in participating in activities. Parents can be invited to enter the classroom as soon as they become teachers, and they used to be just bystanders, but now they need to join in to become executives, which is the requirement of kindergartens.

Confidence is a major factor affecting parental participation. Therefore, teachers should help parents to recognize their abilities at the early stage of their participation, increase their confidence, and make future participation smoothly conducted.

Teachers' recognition of parents' ability can be reflected by asking their parents' opinions on some issues and finally adopting their opinions. Interviews with parents show that no matter how highly educated they are, they still realize that they are not a professional person in the curriculum, so they have less suggestions for the curriculum. Only when teachers first establish the awareness that parents are competent can they participate slowly by adopting parents' opinions to build confidence in participation in the curriculum and make parents feel welcome.

\section{Countermeasures and suggestions}

Guide curriculum reform with scientific and unique curriculum ideas. Curriculum is the core of kindergarten education, and the curriculum concept has the same strain with the usually saying educational philosophy, the purpose of kindergarten, and the guiding ideology of kindergarten, which is the soul and core of the whole kindergarten curriculum program. In a sense, curriculum is thought. The kindergarten curriculum should be the concrete embodiment of kindergarten's idea of kindergarten management. The concept of curriculum is the most missing link in the kindergarten curriculum program in China, reflecting the weak awareness and level of kindergarten curriculum reform. Some kindergartens do not realize that the "invisible hand" of curriculum concept plays an important role in guiding the whole kindergarten curriculum system, so they neglect the construction of curriculum concept; some kindergartens lack the ability to extract and summarize experience. Although after several years of curriculum reform practice, they still do not have a clear curriculum concept that can reflect the characteristics of kindergartens. Without the guidance of scientific and unique curriculum concepts, the practice of kindergarten curriculum reform has no clear direction and goals, and the curriculum content and resources cannot be effectively integrated.

Effectively integrate the content of curriculum reform. From a macroscopic point of view, the principal curriculum and individualized curriculum in kindergarten curriculum reform need the integration of curriculum ideas and curriculum objectives. This method can not only avoid the blindness and arbitrariness of curriculum design, but also make the curriculum content interrelated and complementary, forming a joint educational effort to achieve curriculum objectives. The individualized curriculum developed and set up by kindergartens according to the resources, advantages and the characteristics of children's development should be closely around the concept of kindergarten curriculum and the overall goal of the kindergarten curriculum. From a microscopic point of view, kindergartens need to integrate the contents of various fields with themes, fields or projects, as well as the curriculum contents and resources of regional activities, environmental creation, and family cooperation.

Adhere to the diversification of curriculum reform. The implementation of kindergarten curriculum reform includes daily life activities, teaching activities, environment creation and family 
cooperation. Each aspect contains rich curriculum resources, which can exert positive educational influence on children. Kindergartens should establish a correct view of curriculum, attach importance to the value of various educational methods for the development of young children, and strive to overcome the shortcomings of education based on a single teaching activity. Kindergartens should realize the important value of environment in children's development and kindergarten curriculum, and create a full range of educational life, games and learning environment for children. Through the full interaction between children and their surroundings, their physical and mental development can be developed in an all-round way. The environmental creation of kindergartens should not only be separated from the simple beautification and decoration, but also attach importance to the position and role of children in environmental creation, and actively mobilize children and teachers to participate in environmental creation activities.

\section{Conclusion}

Kindergarten curriculum reform is an essential part in kindergarten education. Parents, as the basic educator and curriculum purchaser and evaluator, play an important role in kindergarten curriculum reform. In order to promote the kindergarten curriculum reform, firstly, the relationship between family and kindergarten curriculum reform is analyzed, suggesting that family is closely related to curriculum reform. Secondly, parents are enabled to participate in the curriculum reform because parents are the important factor affecting the implementation of curriculum reform. At last, in view of the problems existing in kindergarten curriculum reform, some countermeasures are put forward. The successful kindergarten curriculum reform requires the joint efforts of teachers, parents and governments. Teachers and governments should create a good environment for the implementation of kindergarten curriculum reform, and parents should actively participate in the kindergarten curriculum reform and provide help and support.

\section{References}

[1] Li, H., \& Chen, J. J. (2017). Evolution of the early childhood curriculum in China: The impact of social and cultural factors on revolution and innovation. Early Child Development and Care, 187(10), 1471-1483. DOI: doi.org/10.1080/03004430.2016.1220373

[2] Hu, B. Y. (2015). Comparing cultural differences in two quality measures in Chinese kindergartens: The early childhood environment rating scale-revised and the kindergarten quality rating system. Compare: A Journal of Comparative and International education, 45(1), 94-117. DOI: 10.1080/03057925.2013.841468

[3] Hu, B. Y., Dieker, L., Yang, Y., \& Yang, N. (2016). The quality of classroom experiences in Chinese kindergarten classrooms across settings and learning activities: Implications for teacher preparation. Teaching and Teacher Education, 57, 39-50. DOI: 10.1016/j.tate.2016.03.001

[4] Tan, C. T. (2017). Enhancing the quality of kindergarten education in Singapore: policies and strategies in the 21st century. International Journal of Child Care and Education Policy, 11(1), 7. DOI: 10.1186/s40723-017-0033-y

[5] Nyland, B., \& Ng, J. (2016). International perspectives on early childhood curriculum changes in Singapore and Australia. European Early Childhood Education Research Journal, 24(3), 465-476. DOI: 10.1080/1350293x.2015.1102416

[6] Prendergast, M., \& Treacy, P. (2018). Curriculum reform in Irish secondary schools-a focus on algebra. Journal of Curriculum Studies, 50(1), 126-143. DOI: doi.org/10.1080/00220272.2017.1313315

[7] Polly, D., Wang, C., Lambert, R., Martin, C., McGee, J. R., Pugalee, D., \& Lehew, A. (2017). Supporting Kindergarten teachers' mathematics instruction and student achievement through a curriculum-based professional development program. Early Childhood Education Journal, 45(1), 121-131.DOI: 10.1007/s10643-013-0605-6

[8] Ryder, J. (2015). Being professional: accountability and authority in teachers' responses to science curriculum reform. Studies in Science Education, 51(1), 87-120. DOI: 10.1080/03057267.2014.1001629 